\title{
New York state health care provider participation in clinical trials: a brief report
}

\author{
Pathu Sriphanlop', Danielle M. Crookes ${ }^{1}$, Karen Demairo² ${ }^{2}$ Darryl Somayaji ${ }^{3}$, Maureen Killackey ${ }^{4}$, Anita McFarlane ${ }^{5}$, Jean LePere ${ }^{6}$ and \\ Lina Jandorf ${ }^{*}$
}

*Correspondence: lina.jandorf@mssm.edu

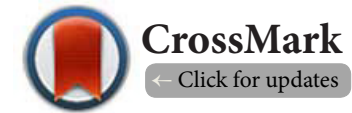

'Department of Oncological Sciences, Icahn School of Medicine at Mount Sinai, New York, USA.

${ }^{2}$ The Leukemia \& Lymphoma Society, Long Island 1324 Motor Parkway Suite, Hauppauge, New York, USA.

${ }^{3}$ Roswell Park Cancer Institute, Elm and Carlton Streets Buffalo, New York, USA.

${ }^{4}$ Cornell Weill Medical College, York Avenue, New York, USA.

${ }^{5}$ The Greater New York City Affiliate of Susan G. Komen for the Cure 470 Seventh Avenue, New York, USA.

${ }^{6}$ Memorial Sloan-Kettering Cancer Center, York Avenue New York, USA.

\begin{abstract}
Although health care providers are integral to the recruitment and enrollment of cancer patients in clinical trials, there is limited literature which has explored the differences between personal and practice characteristics of providers who participate and do not participate in clinical trials. Because little is known about these differences, this exploratory study sought to better understand the perceived barriers to participation among New York State providers. One hundred health care providers responded to the online survey. Respondents were predominantly male, between the ages of 50 and 64, White, have practiced for more than 20 years, and spoke only English. About half have conducted or been involved in a clinical trial. More than half reported that there are barriers to their participation in clinical research including time constraints, personnel needs, infrastructural needs, and a lack of access. While more research, with a larger sample is needed, this study provides evidence to the many of barriers providers face when considering their participation in clinical trials, with infrastructure being the most major. Findings suggest that infrastructural and personnel support could potentially increase clinical trial participation by health care providers.
\end{abstract}

Keywords: Clinical trials, health care providers, cancer

\section{Introduction}

To advance science, clinical trials are essential to ensuring the efficient and effective translation of research. Yet, given the importance of clinical research, only $2 \%$ to $4 \%$ of cancer patients participate in clinical trials $[\mathbf{1 , 2}]$. It has been recommended that a component of treatment planning should include a discussion between physicians and newly diagnosed and current patients about participating in clinical trials specific for their diagnosis and potential benefit of their health, yet only $10 \%$ to $20 \%$ of cancer patients are actually informed about clinical trials [2-4]. The role of health care providers in clinical trials is integral, however, there are limited studies which have examined providers' attitudes, knowledge, and practice regarding clinical trial participation [5-7].
We aimed to learn more about the experiences with and perceptions about cancer clinical trials among health care professionals who might interact with cancer patients. We wanted to identify the characteristics of health care providers in New York State who have participated in clinical trials and those who have not. We were also interested in the perceived barriers and facilitators to provider participation and patient enrollment in cancer clinical trials from the vantage point of health care providers.

\section{Methods}

We developed a brief online questionnaire that was sent (via a link) to health care providers in New York State. An email invitation was sent to existing listservs and contacts from the New York State Cancer Consortium and other medical organi- 
zations and institutions across New York State. Surveys were administered through SurveyMonkey ${ }^{\mathbb{B}}$ and were estimated to take less than 15 minutes to complete.Surveys were collected between January 2013 to April 2013.

The eligibility criteria were: health care providers, both traditional (e.g., physician, nurse, advance practice nurse, physician assistant) and non-traditional (e.g., social workers), in New York State who care for or interact with patients who have had or have cancer, aged 18 and over, and can read and write in English.

\section{Measures}

The 21-item survey captured respondent's demographic characteristics $(\mathrm{N}=6)$, health care practice characteristics $(\mathrm{N}=8)$, and experiences with and opinions about clinical trials and the barriers to and facilitators for participating in clinical trials $(\mathrm{N}=7)$.

\section{Demographic characteristics}

Respondents were asked about their demographic characteristics such as gender, age, race/ethnicity, health care degree, and language.

\section{Health care practice characteristics}

Eight questions asked health care providers about the setting in which they provide care to cancer patients. These questions include: primary health care specialty, number of offices they see patients, location of these offices, type of community the serve (i.e., urban, suburban, rural), type of practice setting (e.g., private, community health clinic, academic medical center, cancer center, Veterans Affairs), length of practice, the race/ ethnicity and gender distribution of their patients, and number of patients they see in a week.

\section{Experiences and opinions about clinical trials}

A primary variable in this study was their past or present involvement in clinical trials. For those who have had experience with clinical trials, we asked about the roles they had in clinical trials (i.e., Principal Investigator, Co-investigator, other) and the average number of patients they refer into clinical trials per year. For those without clinical trial experience, we asked if they were interested in participating in clinical trials. Lastly, they were allowed to provide open-ended answers to reasons why they want to participate in clinical trials.

\section{Barriers to participating in clinical trials}

Respondents also answered whether or not they believe there were barriers to their own participation in clinical trials and selected what these barriers were, such as lack of access, infrastructural needs in the office, lack of experience conducting clinical trials, time constraints, and unwillingness of patients.

\section{Barriers and facilitators for patients to participate in clinical trials}

Health care providers were asked about perceived barriers that keep their patients from participating in clinical trials including medical mistrust, cultural/religious barriers, language/literacy barriers, potential side effects, and lack of insurance or ability to pay. They were also able to provide open-ended answers to the top three factors that would motivate patients to volunteer to participate in clinical research.

\section{Results \\ Characteristics of respondents}

One hundred health care providers responded to the survey. The majority of the participants were aged 50 to 64 (63\%), 15\% were aged 18 to $39,12 \%$ were aged 40 to 49 , and $9 \%$ were 65 or older. Respondents were predominantly male $(74.7 \%)$, between the ages of 50 and $64(63.3 \%)$, White $(84.4 \%)$, and spoke only English (73.1\%). The sample included residents of 9 of the 11 New York State regions: Long Island (37.1\%), New York City (27.4\%), Hudson Valley (9.7\%), Finger Lakes (8.1\%), CapitalSaratoga (4.8\%), Central Leatherstocking (4.8\%), ChautauquaAllegheny (3.2\%), The Adirondacks (3.2\%), and Niagara Frontier (1.6\%). $37.5 \%$ of the sample were MDs, $38.5 \%$ were RNs, and $24.0 \%$ had other degrees (PA, NP, CNS, MSW, LCSW, LMSW) or multiple degrees. Provider demographic characteristics are presented in Table 1.

\section{Health care characteristics}

The majority of respondents (52.5\%) did not specialize in oncology. Among those in the oncology specialty, most practiced in medical oncology (65.1\%) followed by surgical oncology (18.6\%), radiation oncology (11.6\%), and pediatric oncology (4.7\%). Almost half $(43.7 \%)$ of the sample practiced in a suburban community, $33.3 \%$ in an urban community, $13.8 \%$ in a rural community, and $9.2 \%$ in a combination of suburban, urban, and/or rural community. A majority of the respondents have practiced for more than 20 years $(60.5 \%)$, followed by 6 to 20 years $(27.2 \%)$, and 5 years or less (12.3\%). Providers' health care and practice characteristics are presented in Table 2.

\section{Findings}

Thirty-one respondents did not reply to the question about participation in clinical trials. Of the 69 respondents who responded, $50.7 \%$ have conducted or been involved in a clinical trial. Among those who have participated, $42.9 \%$ were involved as Co-Investigators, $2.9 \%$ as Primary Investigators, $14.3 \%$ as both Co-Investigators and Primary Investigators, and $40 \%$ were involved in other capacities (e.g., research assistant, data collector). More than half (59.4\%) reported that there were barriers to their participation in clinical research. These respondents reported these barriers to be time constraints $(60.5 \%)$, personnel needs (57.9\%), infrastructural needs (47.4\%), a lack of access to patient population and to getting involved in clinical trials (44.7\%), lack of experience conducting trials (39.5\%), lack of incentive from grants $(28.9 \%)$, and unwillingness of patients to participate (21.1\%).

\section{Limitations}

The low survey response rate potentially limits the interpretation 
Table 1. Demographic characteristics of survey respondents $(\mathrm{N}=100)$.

\begin{tabular}{|c|c|c|c|c|c|c|}
\hline & \multicolumn{2}{|l|}{ Total } & \multicolumn{2}{|c|}{$\begin{array}{l}\text { Have } \\
\text { Participated }\end{array}$} & \multicolumn{2}{|c|}{$\begin{array}{l}\text { Have Not } \\
\text { Participated }\end{array}$} \\
\hline & $\mathrm{N}=100$ & $\%$ & $\mathrm{~N}=35$ & $\%$ & $\mathrm{~N}=34$ & $\%$ \\
\hline \multicolumn{7}{|l|}{ Age } \\
\hline $18-39$ & 15 & 15.3 & 5 & 14.7 & 7 & 20.6 \\
\hline $40-49$ & 12 & 12.2 & 5 & 14.7 & 5 & 14.7 \\
\hline $50-64$ & 62 & 63.3 & 22 & 64.7 & 20 & 58.8 \\
\hline 65 or older & 9 & 9.2 & 2 & 5.9 & 2 & 5.9 \\
\hline \multicolumn{7}{|l|}{ Gender } \\
\hline Male & 74 & 74.7 & 23 & 67.6 & 26 & 76.5 \\
\hline Female & 25 & 25.3 & 11 & 32.4 & 8 & 23.5 \\
\hline \multicolumn{7}{|l|}{ Race } \\
\hline Black & 4 & 4.2 & 0 & 0.0 & 3 & 9.1 \\
\hline White & 81 & 84.4 & 29 & 87.9 & 26 & 78.8 \\
\hline Asian & 2 & 2.1 & 2 & 6.1 & 0 & 0.0 \\
\hline Hispanic & 6 & 6.3 & 0 & 0.0 & 4 & 12.1 \\
\hline Other & 3 & 3.1 & 2 & 6.1 & 0 & 0.0 \\
\hline \multicolumn{7}{|l|}{ Location of office(s) } \\
\hline Capital-Saratoga & 3 & 4.8 & 1 & 3.4 & 2 & 8.0 \\
\hline $\begin{array}{l}\text { Central Leather- } \\
\text { stocking }\end{array}$ & 3 & 4.8 & 0 & 0.0 & 2 & 8.0 \\
\hline $\begin{array}{l}\text { Chautauqua- } \\
\text { Allegheny }\end{array}$ & 2 & 3.2 & 1 & 3.4 & 1 & 4.0 \\
\hline Finger Lakes & 5 & 8.1 & 4 & 13.8 & 1 & 4.0 \\
\hline Hudson Valley & 6 & 9.7 & 1 & 3.4 & 4 & 16.0 \\
\hline Long Island & 23 & 37.1 & 11 & 37.9 & 8 & 32.0 \\
\hline New York City & 17 & 27.4 & 8 & 27.6 & 7 & 28.0 \\
\hline Niagara Frontier & 1 & 1.6 & 1 & 3.4 & 0 & 0.0 \\
\hline The Adirondacks & 2 & 3.2 & 2 & 6.9 & 0 & 0.0 \\
\hline \multicolumn{7}{|c|}{ Language(s) Spoken } \\
\hline English only & 57 & 73.1 & 21 & 75.0 & 18 & 66.7 \\
\hline English and Spanish & 10 & 12.8 & 3 & 10.7 & 6 & 22.2 \\
\hline $\begin{array}{l}\text { English and other, } \\
\text { or more than two } \\
\text { languages }\end{array}$ & 11 & 14.1 & 4 & 14.3 & 3 & 11.1 \\
\hline \multicolumn{7}{|l|}{ Healthcare Degree } \\
\hline $\mathrm{MD}$ & 36 & 37.5 & 16 & 47.1 & 13 & 40.6 \\
\hline $\mathrm{RN}$ & 37 & 38.5 & 11 & 32.4 & 11 & 34.4 \\
\hline $\begin{array}{l}\text { PA, NP, CNS, other, } \\
\text { or multiple degrees }\end{array}$ & 23 & 24.0 & 7 & 20.6 & 8 & 25.0 \\
\hline
\end{tabular}

of these findings. Because we sent the survey out to numerous listserves statewide, we do not know the number of unique receipents and are unable to report this. Additionally, sample may not be representative of all health care providers in New York State. Despite these limitations, these preliminary findings
Table 2. Health care characteristics of survey respondents $(\mathrm{N}=100)$.

\begin{tabular}{|c|c|c|c|c|c|c|}
\hline & \multicolumn{2}{|l|}{ Total } & \multicolumn{2}{|c|}{$\begin{array}{l}\text { Have } \\
\text { Participated }\end{array}$} & \multicolumn{2}{|c|}{$\begin{array}{l}\text { Have Not } \\
\text { Participated }\end{array}$} \\
\hline & $\mathrm{N}=100$ & $\%$ & $\mathrm{~N}=35$ & $\%$ & $\mathrm{~N}=34$ & $\%$ \\
\hline \multicolumn{7}{|l|}{ Healthcare specialty } \\
\hline Oncology & 43 & 47.8 & 19 & 55.9 & 10 & 32.3 \\
\hline Non-oncology & 47 & 52.2 & 15 & 44.1 & 21 & 67.7 \\
\hline \multicolumn{7}{|l|}{ Oncology specialty } \\
\hline Medical Oncology & 28 & 65.1 & 11 & 57.9 & 7 & 70.0 \\
\hline Pediatric Oncology & 2 & 4.7 & 0 & 0.0 & 1 & 10.0 \\
\hline Radiation Oncology & 5 & 11.6 & 2 & 10.5 & 1 & 10.0 \\
\hline Surgical Oncology & 8 & 18.6 & 6 & 31.6 & 1 & 10.0 \\
\hline \multicolumn{7}{|l|}{ Amount of offices } \\
\hline $\begin{array}{l}\text { Zero, does not see } \\
\text { patients }\end{array}$ & 20 & 22.7 & 3 & 8.8 & 5 & 16.7 \\
\hline One & 50 & 56.8 & 21 & 61.8 & 21 & 70.0 \\
\hline Two or more & 18 & 20.5 & 10 & 29.4 & 4 & 13.3 \\
\hline \multicolumn{7}{|c|}{ Type of medical community } \\
\hline Urban & 29 & 33.3 & 14 & 41.2 & 9 & 28.1 \\
\hline Suburban & 38 & 43.7 & 12 & 35.3 & 15 & 46.9 \\
\hline Rural & 12 & 13.8 & 6 & 17.6 & 5 & 15.6 \\
\hline $\begin{array}{l}\text { Combination of } \\
\text { urban, suburban, } \\
\text { and rural }\end{array}$ & 8 & 9.2 & 2 & 5.9 & 3 & 9.4 \\
\hline \multicolumn{7}{|l|}{ Length of practice } \\
\hline 5 years or less & 10 & 12.3 & 5 & 15.2 & 5 & 16.7 \\
\hline 6 to 20 years & 22 & 27.2 & 6 & 18.2 & 12 & 40.0 \\
\hline More than 20 years & 49 & 60.5 & 22 & 66.7 & 13 & 43.3 \\
\hline \multicolumn{7}{|c|}{$\begin{array}{l}\text { Does respondent find that there are barriers to their } \\
\text { participation in clinical research? }\end{array}$} \\
\hline Yes & 38 & 59.4 & 21 & 61.8 & 17 & 56.7 \\
\hline No & 26 & 40.6 & 13 & 38.2 & 13 & 43.3 \\
\hline
\end{tabular}

Types of Barriers (reported by those who answered yes above; select all that apply)

\begin{tabular}{lllllll}
\hline Lack of access & 17 & 44.7 & 10 & 47.6 & 7 & 41.2 \\
Infrastructural needs & 18 & 47.4 & 13 & 61.9 & 5 & 29.4 \\
Lack of experience & 15 & 39.5 & 5 & 23.8 & 10 & 58.8 \\
Personnel needs & 22 & 57.9 & 15 & 71.4 & 7 & 41.2 \\
Time constraints & 23 & 60.5 & 13 & 61.9 & 10 & 58.8 \\
$\begin{array}{l}\text { Incentives not worth } \\
\text { the effort }\end{array}$ & 11 & 28.9 & 9 & 42.9 & 2 & 11.8 \\
Patients are unwilling & 8 & 21.1 & 2 & 9.5 & 6 & 35.3 \\
\hline
\end{tabular}

have implications for future strategies and messages to increase health provider's participation in clinical trials.

\section{Discussion}

Despite the above mentioned limitations, this initial study 
comparing personal and practice characteristics of health care providers who participate and do not participate in clinical research offers several insights about the perceived barriers of participation among health care providers in New York State. For instance, a majority of respondents identified time constraints, personnel needs, and infrastructural needs to be the biggest barriers to their participation in clinical research. Only $21 \%$ of respondents felt patients were unwilling to participate. This finding can inform future strategies in training of personnel and additional allocation of resources in funding opportunities. More research is needed to examine these barriers and identify effective ways to promote clinical trial participation among health care providers.

\section{Competing interests}

The authors declare that they have no competing interests.

\section{Authors' contributions}

Pathu Sriphanlop was primarily responsible for the literature review, writing, data analysis, and preparing tables. Danielle Crookes assisted in the data collection and editing the manuscript. Karen Demairo, Darryl Somayaji3, Maureen Killackey, Anita McFarlane, Jean LePere and Lina Jandorf helped edit and proofread the manuscript and provided valuable feedback.

\section{Acknowledgement}

We would like to acknowledge the support of the New York State Cancer Consortium Steering Committee, which approved of and encouraged the execution of this project. The New York State Cancer Consortium (NYSCC) is a statewide coalition of organizations charged with development and implementation of the state's Comprehensive Cancer Control Plan. Thus, a NYSCC subcommittee was formed to better understand the attitudes and barriers to clinical trial enrollment in the state and produced this report. We also thank Lisa Ward from the Leukemia \& Lymphoma Society for preparing the online survey.

\section{Publication history}

Editor: Paul J. Higgins, Albany Medical College, USA.

Received: 16 November 2015 Revised: 21 December 2015

Accepted: 05 January 2016 Published: 13 January 2016

\section{References}

1. Michaels M, Weiss ES, Guidry JA, Blakeney N, Swords L, Gibbs B, Yeun S, Rytkonen B, Goodman R, Jarama SL, Greene AL and Patel S. "The promise of community-based advocacy and education efforts for increasing cancer clinical trials accrual". J Cancer Educ. 2012; 27:67-74. | Article | PubMed

2. Klabunde CN, Keating NL, Potosky AL, Ambs A, He Y, Hornbrook MC and Ganz PA. A population-based assessment of specialty physician involvement in cancer clinical trials. J Natl Cancer Inst. 2011; 103:38497. | Article | PubMed Abstract | PubMed FullText

3. Fenton L, Maureen R and Herbst R.S. Clinical trial awareness, attitudes, and participation among patients with cancer and oncologists. CommOncol. 2009; 6:207-213.

4. Baer AR, Michaels M, Good MJ and Schapira L. Engaging referring physicians in the clinical trial process. J Oncol Pract. 2012; 8:e8-e10. | Article | PubMed Abstract | PubMed FullText

5. Hudson SV, Momperousse D and Leventhal H. Physician perspectives on cancer clinical trials and barriers to minority recruitment. Cancer Control. 2005; 12 Suppl 2:93-6. I Article I PubMed
6. Lara PN, Jr., Higdon R, Lim N, Kwan K, Tanaka M, Lau DH, Wun T, Welborn J, Meyers FJ, Christensen S, O’Donnell R, Richman C, Scudder SA, Tuscano J, Gandara DR and Lam KS. Prospective evaluation of cancer clinical trial accrual patterns: identifying potential barriers to enrollment. J Clin Oncol. 2001; 19:1728-33. | Article | PubMed Abstract | PubMed FullText

7. Mills EJ, Seely D, Rachlis B, Griffith L, Wu P, Wilson K, Ellis P and Wright $J R$. Barriers to participation in clinical trials of cancer: a meta-analysis and systematic review of patient-reported factors. Lancet Oncol. 2006; 7:141-8. | Article | PubMed

\section{Citation:}

Sriphanlop P, Crookes M.D, Demairo C, Somayaji D, Killackey M, McFarlane A, LePere J and Jandorf L. New York state health care provider participation in clinical trials: a brief report. J Cancer Ther Res. 2016; 5:3. http://dx.doi.org/10.7243/2049-7962-5-3 